\title{
Preservice Education: Perspectives about Integrating Caregivers
}

\author{
Valerie E. Boyer \\ Rehabilitation Institute, Southern Illinois University at Carbondale, Carbondale, IL 62901-4609, USA \\ Correspondence should be addressed to Valerie E. Boyer; valboyer@siu.edu
}

Received 2 June 2014; Revised 15 September 2014; Accepted 19 November 2014; Published 8 December 2014

Academic Editor: Cathy H. Qi

Copyright (C) 2014 Valerie E. Boyer. This is an open access article distributed under the Creative Commons Attribution License, which permits unrestricted use, distribution, and reproduction in any medium, provided the original work is properly cited.

\begin{abstract}
A disconnect is present between philosophical desire to actively involve caregivers in early intervention (EI) and implementation by EI providers. Preservice education may shape beliefs and build knowledge and skills supporting active participation of caregivers. Two graduate clinicians in speech-language pathology completed a practicum with a two-year-old child, Sam, and his family with half of the sessions including active participation by the caregivers. Analysis of progress notes, individual reflections, and interview transcript yielded clinicians reporting beliefs in collaboration with caregivers and building relationships with caregivers as key to involving caregivers. The clinicians demonstrated knowledge regarding intervention techniques with differences in progress notes based on the presence of the caregiver in sessions. This practicum opportunity promoted development of beliefs, knowledge, and skills about actively involving caregivers in early intervention.
\end{abstract}

\section{Introduction}

Early intervention (EI) principles emphasize family-centered models that encourage active participation of families in the therapeutic process for children ages birth to three years old $[1,2]$. Two types of family-centered EI models, relationshipbased and participation-based models of intervention, highlight the integration of intervention into caregiver-child interactions differing from traditional models directed by clinician and focused on clinician-child interactions [3-5]. While these models are not new, there has been continued discussion regarding conceptualization and implementation $[5,6]$. Dunst [6] discussed the historical foundations of collaborative partnerships between families and EI providers beginning in the 1980s and the 1990s. Successful implementation of collaborative partnership includes instructional practices focused on promoting caregiver responsiveness to child-led behavior, assisting caregivers to establish an environment that enables skills to be practiced and helping caregivers to encourage existing skills [6].

Evidence of disconnect exists between philosophical principles and implementation $[7,8]$. Reported observations of EI providers indicate limited focus on promoting caregiver-child interactions while self-report data from EI providers report moderate levels of confidence and frequency in teaching caregiver [9-11]. Investigators reported that EI providers are generally more focused on their role as experts to influence the course of treatment rather than the role of caregiver [8]. EI providers have described active roles of the caregiver to include asking questions, giving input, and expressing wants and needs without including actively facilitating development and participation in routines [8].

Beliefs of providers have been documented to align with decisions about type of practice including the choice between a traditional practice and a practice focused on active participation of the caregiver [12]. Both internal control orientation factors and external control orientation factors are identified as barriers to EI providers working with caregivers as active participants [8]. Internal control factors include confidence of the providers, experience working with families, and lack of formal training $[8,13,14]$. External control orientation factors include caregiver characteristics, expectations, and commitment [8]. Therefore, personnel training needs to address beliefs, knowledge, and skills to overcome these barriers to practice.

Students in professions often associated with EI were included in an investigation of beliefs regarding participation-based services and EI principles [15]. The authors recommended professional development opportunities for both students and professionals that included active learning 
opportunities with reflection related to active involvement of caregivers [15].

Personnel preparation is an opportunity to expose future EI providers to family-centered models during their preservice training $[7,16,17]$. Preservice education occurs prior to a person being certified or licensed [17]. Practicum experiences, or situations in which preservice clinicians work in an applied setting, offer the opportunity to provide intensive training to novices in the field in order to shape their beliefs and build their knowledge and skills [18]. By incorporating elements of family-centered approach to practicum supervision, students learn from the onset of clinical experiences to include caregivers in the therapeutic process. Speech-language pathology clinicians participate in practicum experiences as part of their graduate coursework under the supervision of certified speech-language pathologists (SLP), often a clinical facility connected to a university [19]. These practicum experiences vary in terms of clients with some clinicians provided the opportunity to work with young children under the age of three.

Providing opportunities for preservice clinicians to work directly with caregivers as active participants in therapy sessions is designed to shape clinician beliefs about value of active participation and support development and implementation in a work-like setting with the support of a clinical supervisor. It is necessary to obtain evidence that this intention is born out of practicum experiences. It is critical to document the perspectives of preprofessionals who participate in training to evaluate whether beliefs, knowledge, and skills are influenced by their experiences working with caregivers. The primary focus of the study was to gauge how clinicians view their experience working directly with caregivers while trying to learn clinical skills themselves. The attempt was to gauge both their own beliefs regarding active involvement of the caregiver in therapy and the implementation of this modality in a preservice practicum experience. A secondary focus was to examine clinician data for evidence of skill and knowledge related to implementation of therapy sessions that actively involve caregivers.

\section{Method}

\subsection{Participants}

2.1.1. Clinicians. Two female graduate students in a Communication Science and Disorders program volunteered to participate as clinicians. Neither had a history of service provision to a child age birth to three prior to this clinical assignment. One graduate clinician had prior experience working in a child care facility. Both participants completed a graduate course on language disorders and were in the process of completing a course on working with children from birth to three at the time they started this project. The two students volunteered to participate as clinicians based on prior positive clinical experiences with the supervisor and a desire to obtain a greater number of clinical practicum hours. Students were not graded on this practicum but did earn hours toward their total practicum requirement. Clinicians were selected based on their interest and availability.
The two clinicians were supervised by a certified SLP employed full-time at a medium size, Midwestern University. The supervisor maintained a state credential as an EI provider. The supervisor taught a graduate course on communication disorders in children under three. Human Subjects Committee approval was obtained prior to initiating services with the family.

2.1.2. Family. The child, Sam (All names have been changed to protect client confidentiality.), was a 22 -month-old Caucasian male at the onset of services diagnosed with an expressive language delay. Sam resided with his biological parents and was an only child. He spent significant time with extended family including his maternal grandmother and aunt during daytime hours. The family expressed enthusiasm about participating in therapy sessions and learning about strategies to use with Sam at home. Sam's mother, Lola, and his aunt, Mary, participated in therapy sessions with Sam as caregivers. Both caregivers were college-educated, and both expressed a desire to learn how to help Sam communicate more efficiently. Sam's family was contacted to participate by the supervisor based on their enrollment in speech therapy at the university clinic. They were selected based on Sam's age. The family agreed to participate because of their interest in learning more about how to help Sam and signed written consents to participate. Enrollment in speech therapy at the clinic was not contingent upon participating in the research project.

Results of the Rossetti Infant-Toddler Language Scale [20] indicated that Sam presented with delays in language expression and pragmatics. The percentage of delay was based on a formula dividing age equivalency on the Rossetti by Sam's chronological age and then multiplying by 100 to get a percentage. This percentage of age was subtracted from $100 \%$ to get the percentage of delay. Sam's percentage of delay from language expression was $70 \%$ and that of pragmatic delay was $40 \%$ at the onset of therapy. Results from the Rossetti InfantToddler Language Scale for language comprehension were within normal limits and play skills were minimally delayed at $15 \%$. At the request of the family, Sam was screened for signs of autism spectrum disorder by an experienced SLP in the area of autism spectrum disorder with results negative. Concurrent with speech therapy conducted at the university training facility, Sam's family received developmental therapy at home two days per week. Developmental therapy was designed to promote general development including communication during the course of the case study.

2.2. Therapy Sessions. The clinicians provided therapy at a university clinic two times weekly for approximately 60 minutes per session over two eight-week blocks. Two sessions were cancelled by the family due to client illness resulting in a total of 30 therapy sessions. One weekly session was a traditional session and one was a family-centered session, and each therapy session is described in Table 1 . The familycentered session required the caregiver to actively participate in therapy session. During the session with a caregiver, the graduate clinicians focused on providing instruction to the caregiver to elicit turn-taking and communication between 
TABLE 1: Comparison of therapy sessions.

\begin{tabular}{llll}
\hline Session type & Frequency & Description & Role of clinician \\
\hline Family-centered & 1 time per week & $\begin{array}{l}\text { Active participation of the caregiver to promote communication } \\
\text { focused on caregiver interacting directly with the child while the } \\
\text { clinician is focused on promoting caregiver-child interaction }\end{array}$ & $\begin{array}{l}\text { Modescribe, observe, } \\
\text { provide feedback, and solve } \\
\text { problem with caregiver }\end{array}$ \\
\hline Traditional & 1 time per week & $\begin{array}{l}\text { Clinicians interact with client in play-based activities while } \\
\text { caregiver observes or is not present }\end{array}$ & $\begin{array}{l}\text { Model, expand, respond to } \\
\text { client's communication attempts, } \\
\text { and manipulate environment } \\
\text { directly to facilitate } \\
\text { communication }\end{array}$ \\
\hline
\end{tabular}

TABLE 2: Strategies clinicians promoted with caregivers.

\begin{tabular}{lll}
\hline Strategy & How to implement strategy & Examples \\
\hline Caregiver responsiveness & $\begin{array}{l}\text { Follow the child's lead, take turns during play, and } \\
\text { reinforce communication attempts by the child }\end{array}$ & $\begin{array}{l}\text { Praised caregiver when she followed Sam to kitchen } \\
\text { and began to take turns talking on the phone }\end{array}$ \\
\hline Modeling & $\begin{array}{l}\text { Demonstrate words, phrases, and signs and expand } \\
\text { on child's productions }\end{array}$ & $\begin{array}{l}\text { Demonstrated to caregiver how to model the sign } \\
\text { and word for "more" to make requests for toys }\end{array}$ \\
\hline $\begin{array}{l}\text { Environmental } \\
\text { manipulation }\end{array}$ & $\begin{array}{l}\text { Identify highly motivating toys or objects, } \\
\text { manipulate toys to promote communication, and } \\
\text { integrate language into daily routines }\end{array}$ & $\begin{array}{l}\text { Praised caregiver for providing access to preferred } \\
\text { items (i.e., bubbles) after the child said "more } \\
\text { bubbles" }\end{array}$ \\
\hline
\end{tabular}

child and caregiver. The traditional weekly session was not attended by the caregiver reflective of a traditional clinical training model. The caregiver intermittently watched therapy sessions with the supervisor but did not participate. The clinicians provided play-based intervention using the same evidence-based teaching strategies mentioned above to facilitate communication development with Sam. In sessions without a caregiver, clinicians were directly involved in play-based therapy and did not provide instruction to the caregivers. The order of session weekly was alternated to avoid order of presentation effects.

During the initial eight weeks, the focus was on teaching the caregiver to respond to Sam's communication attempts, model and expand verbal and gestural communication including manual signs, facilitate turn-taking by following the child's lead, and manipulate items of interest to promote communication. These strategies were selected based on consistency with which they are used across intervention philosophies and the consistency with which they are recommended in the literature [21-24]. The clinicians described the strategies, modeled the strategies, and provided positive feedback to caregivers when they observed the strategies utilized. See Table 2 for strategies with examples listed. The Rossetti Infant-Toddler Language Scale [20] was administered at the beginning of the second eight-week block to reassess progress and determine goals/objectives. Therapeutic strategies were consistent; however, the primary emphasis in the second eight-week block shifted to focus more on environmental manipulation to elicit communication, expansion of spontaneous communication to more complex forms, and modeling words and phrases. This shift was a result of the child's progress during the first eight weeks of therapy resulting in an increase in spontaneous communication, turn-taking, and imitation.
The two eight-week blocks were separated by a four-week semester break consistent with the clinic schedule. During the four-week break, Sam's family arranged for the clinicians to come to home once a week and play with Sam in order to maintain comfort between the clinicians and Sam. The clinicians and family both reported enjoying the visits, but there was no formal therapy occurring and no data collected during the four-week interval.

The caregivers reported Sam used expressive communication in developmental therapy sessions, but those developmental therapy sessions were typically table-based and clinician led. They described table-based sessions as consisting of play-based activities that could be completed at a table such as puzzles, pretending to play with a farm, and art activities. Caregivers' report regarding verbal behavior was a positive indication that behavior observed during the case study was generalized to other environments and a reliable estimate of the child's communication skills.

Alternating between traditional and family-centered approaches to sessions provided the opportunity for the clinicians to practice direct intervention with a child, provided them with a point of comparison between two different approaches to intervention, and ensured that Sam would receive services consistent with the standard of care at the facility. Supervision was provided on-site. The supervisor was in the therapy room for the first two weeks to provide modeling and immediate feedback. The remaining supervision was done using a two-way mirror. The supervisor provided written and verbal feedback to clinicians in order to encourage use of specific teaching strategies.

2.3. Measures. Clinicians wrote daily progress notes at the end of each therapy session on carbon copies. One copy was for the caregiver and one was for clinician records. All 
TABLE 3: Sources for clinicians' perspectives.

\begin{tabular}{lll}
\hline Source & Timing & Manner \\
\hline Session progress notes & End of each therapy session & Clinicians collaboratively wrote progress notes \\
\hline Session reflections & Following therapy session & $\begin{array}{l}\text { Each clinician independently rated session and described } \\
\text { strengths and challenges of session }\end{array}$ \\
\hline Clinician interview & At the conclusion of practicum & $\begin{array}{l}\text { Clinicians jointly participated in semistructured interview with } \\
\text { supervisor }\end{array}$ \\
\hline
\end{tabular}

progress notes were kept as this document was considered the official record of each therapy session. Salisbury and colleagues [25] used progress notes as one data source to evaluate their professional development training program advocating for notes as evidence of quality of sessions. Both clinicians had previous experience generating session progress notes following therapy sessions. Of the 28 progress notes analyzed, 13 were from sessions with the caregiver and 15 were sessions without the caregiver.

The clinicians also wrote individual reflections following each session. A standard form for reflections consisted of the clinicians rating their session on 1-to-5 scale with 5 being an outstanding session and 1 being a poor session, providing a written rationale for the rating and then reflecting on the strengths and challenges of that session. The supervisor randomly collected ten clinician reflections to analyze including six reflections from sessions with the caregiver and four reflections from sessions without the caregiver. Individual reflections offered a data source focused on self-evaluation by each clinician individually. Random collection was designed to promote the clinicians to be more relaxed and open in their writing because not all entries would be reviewed. Progress notes and individual reflections were qualitative indicators of clinicians' beliefs and were also reviewed for knowledge and skill acquisition.

At the conclusion of the project, both clinicians participated jointly in an interview with their supervisor regarding their experience with Sam's family. The semistructured, openended interview enabled a discussion of strengths, challenges, and recommendations for future clinicians. The supervisor began the interview by asking the clinicians to discuss their overall impressions of the practicum. This provided a starting point for a conversation lasting approximately 30 minutes. The interview was videotaped and transcribed later by the supervisor.

2.4. Data Analysis. A qualitative, case study design provided the opportunity to learn more about clinician perspectives regarding active involvement of caregivers in therapy sessions [26]. Table 3 describes sources of data analyzed and methods for collection. Triangulation of data was obtained by analyzing clinician reflections, progress notes from sessions, and interview transcriptions over time and from multiple clinicians $[27,28]$. The supervisor analyzed only data generated by the clinicians, because the primary focus of this project was clinician voice through interview and written documents.

All data sources were analyzed by the supervisor for themes that reflected the clinicians' perspectives of actively involving the caregiver. Initially the supervisor read through all the documents including the transcript from the interview and underlined key terms that regularly occurred in an effort to identify patterns that existed in the three data sources [28]. Open coding was utilized as a strategy for categorization analysis to enable the supervisor to highlight data that seemed to the supervisor most significant [29]. Next, the supervisor identified categories that described participants' beliefs and knowledge demonstrated, described by Maxwell as substantive categories [29]. Substantive categories were linked across data sources to form themes with examples to support themes identified in individual examples in progress notes, reflections, and interview transcripts [29]. The use of multiple data sources over a 16-week period increased the richness of the data [29]. Finally clinicians were contacted to review their themes. Use of member checks provides validation of the responses and is described by Maxwell as the most important method of ruling out misinterpretation [29]. Both clinicians completed the review and indicated the themes were representative of their perspectives on the practicum.

\section{Results}

Themes emerged from analyzing the interview transcript, progress notes, and individual reflections including (a) the importance of collaboration; (b) the increased confidence with development of relationships between caregiver, clinician, and child; (c) the specific intervention techniques described frequently by the clinicians; and (d) differences in session progress notes written by the clinician based on the presence or absence of the caregiver. The collaboration theme and relationship building theme are responses to the primary focus of the study on gauging clinician perspectives on their experience working directly with caregivers. The intervention techniques and differences in progress notes reflect the secondary focus, clinical skill acquisition. Themes regarding the importance of collaboration and increased confidence as relationships development were central to documenting the clinicians' beliefs about caregiver involvement and perspectives on the active involvement of caregivers in a practicum setting. Both clinicians reported positive experience with the practicum, with one clinician describing it as "great" in the final interview. The clinicians indicated beliefs that caregivers could actively promote communication in therapy sessions specifically noting in the final interview that working with Sam and the caregiver provided the clinicians with more opportunities to make change. They described the practicum as initially "challenging," but their themes indicated some core elements that enabled improved confidence and strengthened beliefs about caregivers. The clinicians' 
TABLE 4: Themes and examples of perspectives of clinicians.

\begin{tabular}{|c|c|c|}
\hline Theme & Evidence & Source \\
\hline \multirow[b]{2}{*}{ Collaboration } & "We did a lot of using each other to facilitate things" & Interview \\
\hline & $\begin{array}{l}\text { "I was very pleased. We allowed the client to have primary interaction with the } \\
\text { caregiver." }\end{array}$ & Reflection \\
\hline \multirow{2}{*}{ Relationship-building } & $\begin{array}{l}\text { "At the beginning that (working with the caregiver) was a really big challenge for } \\
\text { me... especially because we didn't know them very well at first." }\end{array}$ & Interview \\
\hline & $\begin{array}{l}\text { "I like the two days, with Lola, if you are explaining how to prompt it is a good } \\
\text { way to see that carryover and reinforce it." }\end{array}$ & Interview \\
\hline \multirow{2}{*}{ Intervention techniques } & $\begin{array}{l}\text { "Examples of manipulating, modeling, and expansion were given to the } \\
\text { caregiver." }\end{array}$ & Progress note \\
\hline & $\begin{array}{l}\text { "An excellent job of facilitating communication by modeling appropriately and } \\
\text { letting the client finish her sentences." }\end{array}$ & Progress note \\
\hline \multirow{2}{*}{$\begin{array}{l}\text { Differences in records of progress } \\
\text { notes }\end{array}$} & "Continue on expansion on phrases with preferred items." & $\begin{array}{l}\text { Progress note with } \\
\text { caregiver }\end{array}$ \\
\hline & "Caregiver was instructed to model... and reinforce." & $\begin{array}{l}\text { Progress note with } \\
\text { caregiver }\end{array}$ \\
\hline
\end{tabular}

perspectives were rooted in advocacy of collaboration and building relationship with the caregivers to diminish initial reservations about actively involving them in therapy sessions.

A secondary, but important, focus of data analysis was on skill and knowledge development as part of the practicum. Themes about preference of strategies and differences in progress notes provide evidence of growth in knowledge and skills related to active involvement of caregivers in therapy sessions. The clinicians indicated preferences for discussion and noted use of specific strategies in reflections, progress notes, and interview. Their use of strategies indicated implementation of evidence-based practices with session involving caregivers. Their progress notes indicated more focus on caregiver implementation in sessions the caregiver attended. Specific themes are discussed below in greater detail. Table 4 provides a list of themes with specific quotes from the clinicians.

3.1. Theme 1: Collaboration. The first focus on this investigation was on the perspectives of the clinicians regarding working directly with a caregiver in therapy sessions. Collaboration as a theme was described by clinicians as it pertained to the caregiver, each other, and the supervisor. Both clinicians expressed value in collaboration with the caregivers. As one clinician described in sessions reflections "we (caregiver and clinician) were really clicking together". In the final interview, one clinician described the immediate feedback that collaboration provided by stating "if you are explaining how to prompt, it is a good way to see that carryover and reinforce it (the carryover)." By actively collaborating with the caregiver in sessions, the clinicians received immediate feedback and used the collaboration to promote communication. The expansion of collaboration to coclinicians and the supervisor is important to understand for future implementation. Clinicians reported in their reflections that strengths of sessions included working together. They also reported that the modeling and feedback from the supervisor were important for "building their confidence level" as they worked both with Sam and his family. The experience of working with caregivers may not be sufficient unless it is supported by other peers and professionals.

3.2. Theme 2: Relationship Building. Discussions of relationship building are significant for obtaining clinicians' beliefs about active involvement of the caregiver in therapy sessions. Both clinicians reported initial lack of confidence with working with caregivers. They described this lack of confidence as feeling like they were overstepping when teaching the caregiver a specific strategy. One clinician remarked in the interview that "It almost felt like you were trying to tell her how to be a mother instead of how to communicate." Her coclinician followed this statement by saying, "I do not feel like that anymore but at the beginning..." indicating that once a comfort level was established, confidence increased. This increased comfort level was explicitly stated in a session reflection with the statement "strengths for this session include feeling more comfortable engaging with the caregiver." Building a relationship with the caregivers and with Sam seemed to be tied to this increase in clinician comfort and confidence as stated by one clinician, "knew they (caregivers) respect us and know we are professional."

Increased comfort level resulted in positive statements about the quality of sessions for each clinician. One clinician reported that "we allowed the client to have primary interaction with the caregiver" as a strength in a session reflection. While both clinicians rated sessions high in terms of productivity consistently, their rationale changed from an initial focus on physical separation of the child from the caregiver to explore the environment to a later focus on expressive communication and independence. Once there was confidence in the relationships, the clinicians' focus could more directly be placed on facilitating Sam's communication. Their positive beliefs that they could work with caregivers in session appear to be connected with establishing relationships with the caregivers. 
3.3. Theme 3: Intervention Techniques. The second focus of this project was clinical knowledge and skill acquisition. Intervention techniques indicated acquisition of knowledge and skills regarding therapy strategies to utilize when involving caregivers. The clinicians reported specific knowledge of therapeutic strategies including following the child's lead, modeling, expansion, environmental manipulation, contingent responsiveness, and imitation. Examination of documentation from the clinicians revealed some techniques reported consistently. The clinicians reported frequently teaching the caregiver to model, expand on productions, and manipulate the environment to encourage communication. Modeling was commonly documented in the progress notes and reported individually in reflections. The clinicians documented modeling in seven of the progress notes from caregiver sessions. They specifically wrote about teaching caregivers to model appropriately reinforcing modeling that the caregivers utilized, and suggesting modeling communication at home.

Expansion was a term commonly used in conjunction with modeling as one clinician reported in the progress note that "examples of manipulating, modeling, and expansion were given to the caregiver." The same progress note included suggestions for home to "continue working on expanding, modeling, and manipulating for the use of no." Documented use of caregiver expansion was recorded in notes including positive reinforcement of caregiver expansion of vocalizations and expanding words to phrases. One clinician described expansion of Sam's gestures and vocalizations as a specific strength of a session in an individual reflection.

Environmental manipulation to facilitate communication was also mentioned by clinicians. In one progress note, the clinicians praised the caregiver for withholding a preferred item until Sam communicated a request in the form of a manual sign for "more." In a later session, the clinicians praised the caregiver for the same manipulation of a preferred item, but this time they noted the caregiver required verbal production, "I want bubbles," before receiving the preferred item. The clinicians supported the caregivers' use of environmental manipulation, providing specific feedback without using professional jargon.

The clinicians commented on following the child's lead twice in progress notes but also described the strategy as important in their final interview. A session in the second month of therapy included a comment in the progress note on providing instruction to the caregivers to follow the child's lead. In the final month of the project, the clinicians provided written reinforcement to the caregiver for following the child's lead in a session. The clinician once documented following the child's lead as a challenge in session reflection writing, "Sam goes to the farm, but we hand him other toy. We need to model appropriately for the activity he is interested in." They also wrote in a progress note that the caregiver "followed Sam's lead and expanded his vocalization" linking teaching strategies together while providing positive reinforcement for the caregiver use of strategies to promote communication. While following the child's lead was mentioned less than other techniques, it was documented as a teaching strategy with awareness by the clinicians of when it was not optimally utilized in a session. In addition, they described it as something different in this practicum experience compared with others in their final interview.

The language used by clinicians in reflections, progress notes, and the final interview clearly indicated understanding and use of evidence-based strategies related to promoting communication in young children. The consistent evidence of these strategies in notes, reflections, and interviews extends clinicians' positive beliefs regarding active caregiver involvement to specific strategies to teach caregivers.

3.4. Theme 4: Differences in Records of Progress. The final theme also adds to the indications of clinical skill acquisition and how the skill of writing for a home program differed based on the different model of therapy in use. Notes from sessions with the caregiver, present, contained information on teaching techniques, positive reinforcement of the caregiver, and suggestions for home carryover. Comments related directly to caregiver behavior and/or teaching techniques were in seven of the 13 notes from sessions with caregivers compared with only one note out of 15 from sessions without caregivers. For example, the clinicians positively reinforced caregiver behavior in one note by saying that the caregiver did "an excellent job of facilitating communication by modeling appropriately and letting the client finish her sentences." The clinicians provided documentation by writing that "examples of manipulating, modeling, and expansion were given to the caregiver." Suggestions for continuation of strategies at home were recorded in progress notes, documenting "continue on expansion on phrases with preferred items." Notes from traditional sessions without the caregiver recorded Sam's behavior including how much he talked and what he said. The only mention of caregiver behavior in notes from traditional sessions included the following suggestion: "continue working with yes and no and expanding on vocalizations." The presence of the caregiver seemed to promote consideration of caregiver involvement in progress notes. In contrast, the clinicians appeared to overlook caregiver teaching or feedback in session in which the caregiver was absent. The focus instead was on Sam's performance. Active involvement of caregivers appeared to promote a caregiver-child focus not only in actions but in written feedback as well.

\section{Discussion}

The clinicians both described value to the active involvement of caregivers as part of their practicum. Beliefs in collaboration were echoed consistently in reflections and their final interview. The clinicians expressed beliefs that they acquired skills and knowledge through working with caregivers strengthened by collaboration with each other and supported by an experienced supervisor. Building relationships with the caregivers decreased apprehensiveness regarding EI and specifically actively involving caregivers. The value in collaboration with other providers and with the family is inherent in an EI system focused on interdisciplinary teams to the provided intervention [30]. Collaboration in this investigation was linked by the clinicians directly to active involvement of the caregiver in promoting language in therapy 
sessions. The incorporation of active caregiver involvement in therapy session is an aspect of collaboration that has been missing in some literature documenting the beliefs of providers [8]. The ability to recognize the value in this collaboration at the preservice level provides a foundation to value that type of collaboration when working as EI providers.

Shaping the beliefs of preservice students is one way of changing attitudes toward active caregiver participation that may inhibit implementation of these well-established best practices in EI $[6,8,15]$. Both professionals and students in EI fields of study have expressed doubts about active involvement of caregivers and have reported more focus on their own role as experts in influencing the course of intervention $[8,15,31]$. Both clinicians in this practicum expressed and documented positive beliefs about involving caregiver with the assistance of collaboration and relationship building through the practicum.

In this practicum experience, clinicians' internal control orientation factors seemed to be mediated by clinicians' perceptions of external control orientation factors. The clinicians linked personal confidence (internal control factor) to perceptions of what the caregivers think (external control factors). They became more confident in themselves as their own perceptions of the caregivers changed. For example, the clinicians reported initially worrying caregivers might think the clinicians were overstepping their boundaries, but as the relationship developed the clinicians recognized that the caregivers respected and valued their opinions. Actively working with caregivers in therapy sessions enabled this relationship to form and contributed to increased personal confidence as reported by the clinicians.

Any EI provider needs to develop skills of verbalizing what they are doing in order to describe therapeutic or teaching strategies, model strategies, and provide feedback to caregivers utilizing these strategies [32]. Caregivers need to understand effective techniques to assist their child's learning to meet the EI outcome focused on families helping their child develop and learn [33]. The clinicians' writings documented knowledge and skills at describing specific strategies including modeling, expansion, and environmental manipulation, all of which are evidence-based strategies for early intervention [24]. The clinicians reported demonstrating techniques, reinforcing caregiver's behavior in the sessions, and also problem solving issues at home by suggesting the use of these techniques at home. Teaching the clinicians to not only use the strategies but also recognize and verbalize strategies to caregivers assisted the clinicians in adhering to recommendations to include instructional practices in implementation of collaborative partnership [6].

The clinicians documented caregiver behavior including teaching strategies and suggestions for home carryover more frequently when the caregiver was present in the session. Notes from traditional clinician-child sessions were limited in focus on caregiver-child interactions. Intuition might suggest that if the clinicians were actively engaging the caregiver in a therapy session, they would write progress notes with the same focus on caregiver-child interactions in the progress note when the caregiver was present. Written feedback that is consistent with verbalization and modeling of strategies provide the caregivers with an additional mode of information exchange to assist in facilitating communication. Documentation related to specific caregiver behavior to promote communication and recommendations of strategies illustrate knowledge and skills of the clinicians related to active caregiver involvement. While there was a significant difference in documentation in sessions with caregivers, the rate of written feedback focused on caregiver support and teaching could have been greater. Salisbury and colleagues [25] supported the use of progress notes as evidence of skills but documented underreporting by clinicians of caregiverfocused behavior on progress notes. It is possible that our clinicians underreported as well.

4.1. Limitations. There are several limitations including dependence upon clinician data only, the limited number of clinicians, and the characteristics of clinicians. This project only utilized clinicians' documents and interview. To increase the richness of the data analysis, additional observations or field notes could provide feedback on clinicians' use of coaching, problem solving, and observations to determine if clinicians are able to utilize a variety of teaching mechanisms with caregivers $[10,25,33]$. These strategies are part of the professional development related to active involvement of caregivers and documentation of their use would strengthen preservice training as well [25].

This is one small description of how an aspect of EI principles can be integrated into a preprofessional practicum and more investigations are needed regarding the best mechanisms for teaching knowledge and skills to future EI providers. Only two clinicians participated in this practicum experience limiting the participant triangulation of the data. Both volunteered indicating possible positive beliefs about the project initially. The location was a clinical setting and does not meet with EI best practices of a natural environment and limited routine-based intervention in routines beyond play. However, this is a cost-effective model for beginning to integrate EI focus on family-centered practices into clinician practicum experiences.

\section{Conclusion}

While this was a speech-language pathology practicum, the evidence of benefit is significant for other EI providers as well. Strengthening beliefs about the value of caregivers as active participants and the importance of collaboration are critical elements to EI regardless of discipline $[8,25]$. The strategies the clinicians reported using including modeling, environmental manipulation, and caregiver responsiveness also transcend speech-language pathology. SLPs model words and phrases while other discipline experts model movement and play. The challenges facing educating preservice clinicians in speech-language pathology have also been reported in other disciplines [7]. While the specifics regarding setting and timeframe might vary, the need to provide this type of experience is consistent across disciplines.

This was a case study with an enthusiastic and educated family offering the opportunity to expand the clinical practicum experience from focusing only on clinician-child 
relationship to focusing on clinician-caregiver relationships. By documenting clinician perspectives, evidence of shaping beliefs and building knowledge and skills through a clinical practicum model emerged. This expanded focus is consistent with EI philosophical principles and integrates these principles into preservice training. For the clinicians who participated, they perceived the experience as a confidencebuilding experience in working with young children and their families. These results point to opportunity to shape beliefs and facilitate knowledge and skill acquisition as an important role of preservice training.

It appears from clinician feedback in this project that it will take time for clinicians to build relationships with families and those relationships will be the foundation for active involvement in therapy. Use of peer clinicians and a supervisor willing to model and provide feedback is also recommended based on feedback from the clinicians in this practicum. Continuing to obtain the voices of clinicians participating in preservice experiences involving active participation of caregivers is necessary to observe if therapy strategies are integrated into therapy sessions effectively.

\section{Conflict of Interests}

The author declares that there is no conflict of interests regarding the publication of this paper.

\section{References}

[1] American Speech-Language Hearing Association, "Roles and responsibilities of speech-language pathologists in early intervention," Tech. Rep., 2008, http://www.asha.org/policy/GL200800293.htm.

[2] C. Trivette and C. Dunst, "DEC recommended practices: family-based practices," in DEC Recommended Practices: A Comprehensive Guide, S. Sandall, M. L. Hemmeter, B. Smith, and M. McLean, Eds., pp. 107-126, Sopris West, Longmont, Colo, USA, 2005.

[3] P. H. Campbell and L. B. Sawyer, "Supporting learning opportunities in natural settings through participation-based services," Journal of Early Intervention, vol. 29, no. 4, pp. 287-305, 2007.

[4] J. L. Colyvas, L. B. Sawyer, and P. H. Campbell, "Identifying strategies early intervention occupational therapists use to teach caregivers," The American Journal of Occupational Therapy, vol. 64, no. 5, pp. 776-785, 2010.

[5] J. Woods, S. Kashinath, and H. Goldstein, "Effects of embedding caregiver-implemented teaching strategies in daily routines on children's communication outcomes," Journal of Early Intervention, vol. 26, no. 3, pp. 175-193, 2004.

[6] C. J. Dunst, "Revisiting 'rethinking early intervention"' Topics in Early Childhood Special Education, vol. 20, no. 2, pp. 95-104, 2000.

[7] P. H. Campbell, L. Chiarello, M. J. Wilcox, and S. Milbourne, "Preparing therapists as effective practitioners in early intervention," Infants and Young Children, vol. 22, no. 1, pp. 21-31, 2009.

[8] J. L. Fleming, L. B. Sawyer, and P. H. Campbell, "Early intervention providers' perspectives about implementing participationbased practices," Topics in Early Childhood Special Education, vol. 30, no. 4, pp. 233-244, 2011.

[9] S. L. McBride and C. Peterson, "Home-based early intervention with families of children with disabilities: who is doing what?"
Topics in Early Childhood Special Education, vol. 17, no. 2, pp. 209-233, 1997.

[10] C. A. Peterson, G. J. Luze, E. M. Eshbaugh, H.-J. Jeon, K. R. Kantz, and S. L. Mcbride, "Enhancing parent-child interactions through home visiting: promising practice or unfulfilled promise?" Journal of Early Intervention, vol. 29, no. 2, pp. 119140, 2007.

[11] B. E. Sawyer and P. H. Campbell, "Early interventionists' perspectives on teaching caregivers," Journal of Early Intervention, vol. 34, no. 2, pp. 104-124, 2012.

[12] P. H. Campbell and L. B. Sawyer, "Changing early intervention providers' home visiting skills through participation in professional development," Topics in Early Childhood Special Education, vol. 28, no. 4, pp. 219-234, 2009.

[13] E. Bjorck-Akesson and M. Granlund, "Family involvement in assessment and intervention: perceptions of professionals and parents in Sweden," Exceptional Children, vol. 61, pp. 520-535, 1995.

[14] N. W. Pappas, S. McLeod, L. McAllister, and D. McKinnon, "Parental involvement in speech intervention: a national survey, Clinical Linguistics and Phonetics, vol. 22, no. 4-5, pp. 335344, 2008.

[15] L. B. E. Sawyer and P. H. Campbell, "Beliefs about participationbased practices in early intervention," Journal of Early Intervention, vol. 31, no. 4, pp. 326-343, 2009.

[16] E. E. Barton, H. W. Moore, and J. K. Squires, "Preparing speech language pathology students to work in early childhood," Topics in Early Childhood Special Education, vol. 32, no. 1, pp. 4-13, 2012.

[17] M. B. Bruder, C. Mogro-Wilson, V. D. Stayton, and S. L. Dietrich, "The national status of in-service professional development systems for early intervention and early childhood special education practitioners," Infants and Young Children, vol. 22, no. 1, pp. 13-20, 2009.

[18] M. Macy, J. K. Squires, and E. E. Barton, "Providing optimal opportunities: structuring practicum experiences in early intervention and early childhood special education preservice programs," Topics in Early Childhood Special Education, vol. 28, no. 4, pp. 209-218, 2009.

[19] American Speech Language Hearing Association, Standards for Accreditation of Graduate Education Programs in Audiology and Speech-Language Pathology, 2012.

[20] L. M. Rossetti, The Rossetti Infant Toddler Language Scale, Linguisystems, East Moline, Ill, USA, 1990.

[21] L. S. DeThorne, C. J. Johnson, L. Walder, and J. Mahurin-Smith, "When "Simon says" doesn't work: alternatives to imitation for facilitating early speech development," American Journal of Speech-Language Pathology, vol. 18, no. 2, pp. 133-145, 2009.

[22] C. J. Dunst and C. M. Trivette, "Using research evidence to inform and evaluate early childhood intervention practices," Topics in Early Childhood Special Education, vol. 29, no. 1, pp. 40-52, 2009.

[23] M. L. Hemmeter and A. P. Kaiser, "Enhanced milieu teaching: effects of parent-implemented language intervention," Journal of Early Intervention, vol. 18, no. 3, pp. 269-289, 1994.

[24] L. M. Rossetti, Communication Intervention: Birth to Three, Singular-Thompson Learning, San Diego, Calif, USA, 2001.

[25] C. Salisbury, E. Cambray-Engstrom, and J. Woods, "Providers' reported and actual use of coaching strategies in natural environments," Topics in Early Childhood Special Education, vol. 32, no. 2, pp. 88-98, 2012. 
[26] J. S. Damico and N. N. Simmons-Mackie, "Qualitative research and speech-language pathology: a tutorial for the clinical realm," American Journal of Speech-Language Pathology, vol. 12, no. 2, pp. 131-143, 2003.

[27] R. C. Bogdan and S. K. Bilken, Qualitative Research for Education: An Introduction to Theories and Methods, Boston, Mass, USA, Pearson, 5th edition, 2007.

[28] E. Brantlinger, R. Jimenez, J. Klingner, M. Pugach, and V. Richardson, "Qualitative studies in special education," Exceptional Children, vol. 71, no. 2, pp. 195-207, 2005.

[29] J. A. Maxwell, Qualitative Research Design: An Interactive Approach, Sage, Los Angeles, Calif, USA, 2013.

[30] M. Blue-Banning, J. A. Summers, H. C. Frankland, L. L. Nelson, and G. Beegle, "Dimensions of family and professional partnerships: constructive guidelines for collaboration," Exceptional Children, vol. 70, no. 2, pp. 167-184, 2004.

[31] D. Paul and F. P. Roth, "Guiding principles and clinical applications for speech-language pathology practice in early intervention," Language, Speech, and Hearing Services in Schools, vol. 42, no. 3, pp. 320-330, 2011.

[32] J. J. Woods, M. J. Wilcox, M. Friedman, and T. Murch, "Collaborative consultation in natural environments: strategies to enhance family-centered supports and services," Language, Speech, and Hearing Services in Schools, vol. 42, no. 3, pp. 379392, 2011.

[33] D. B. Bailey Jr., M. B. Bruder, K. Hebbeler et al., "Recommended outcomes for families of young children with disabilities," Journal of Early Intervention, vol. 28, no. 4, pp. 227-251, 2006. 

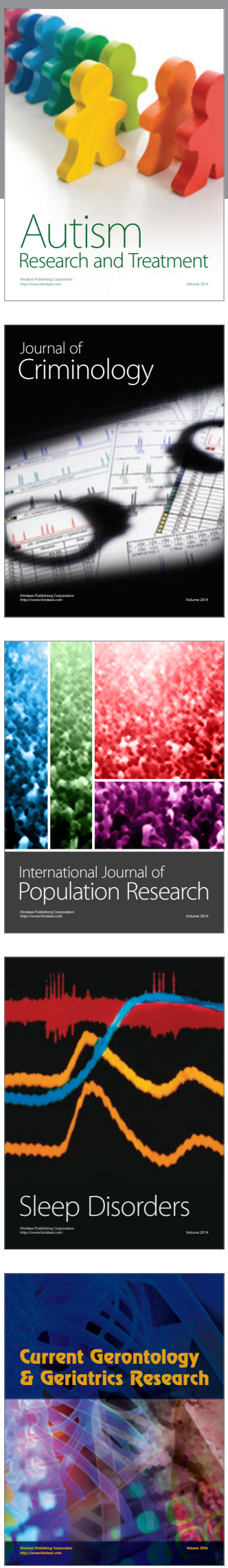
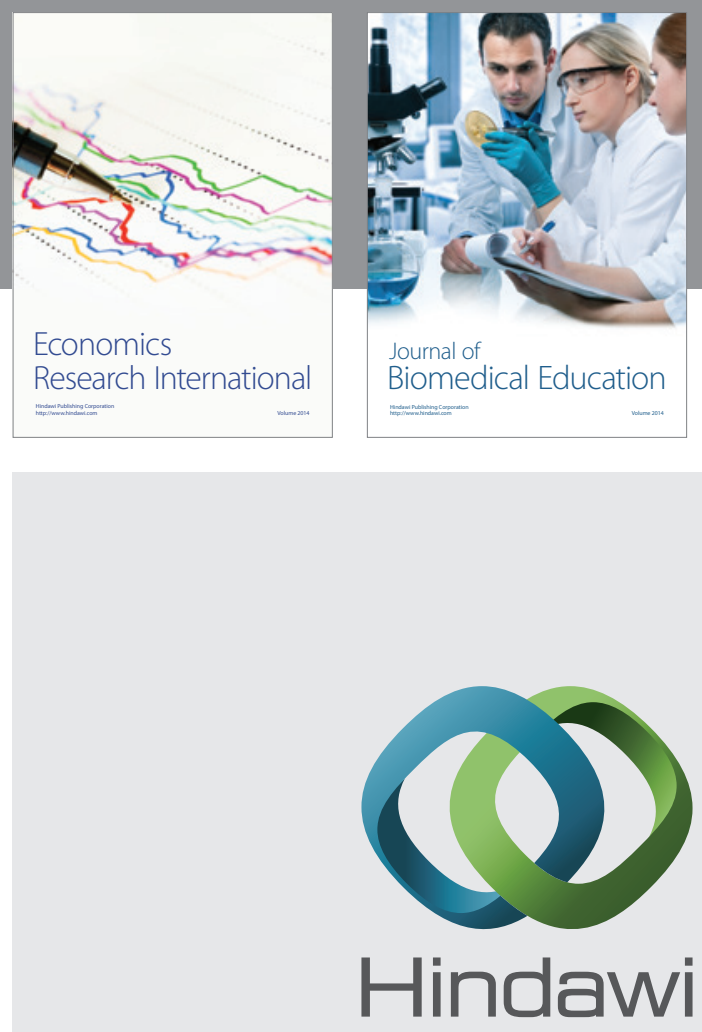

Submit your manuscripts at

http://www.hindawi.com
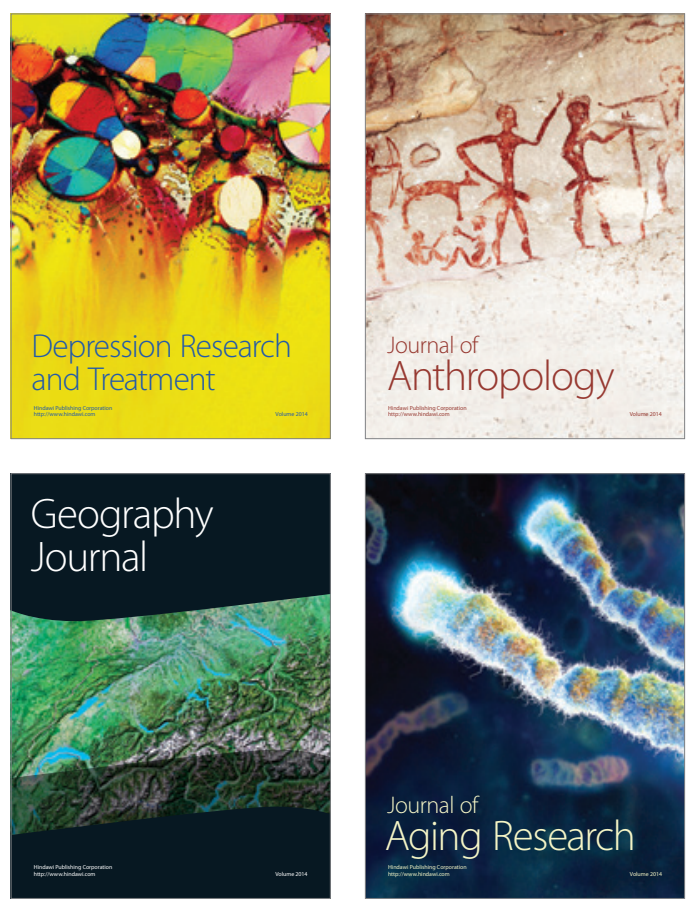
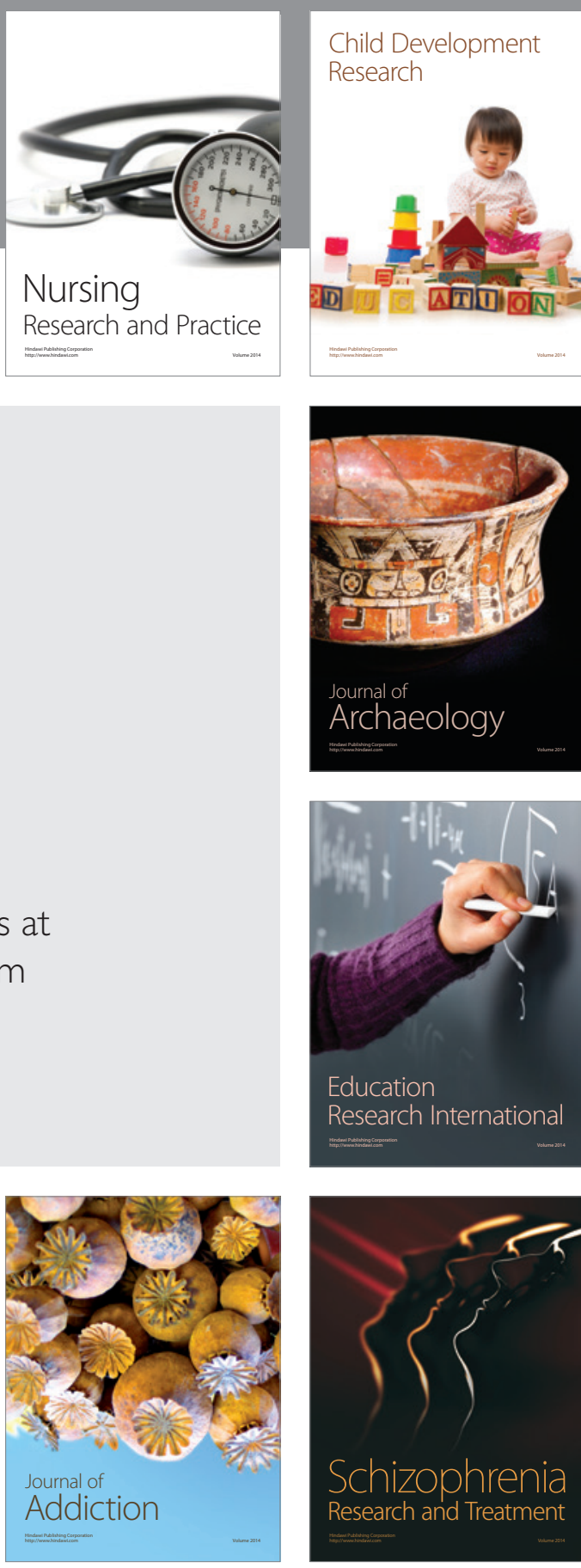

(D)
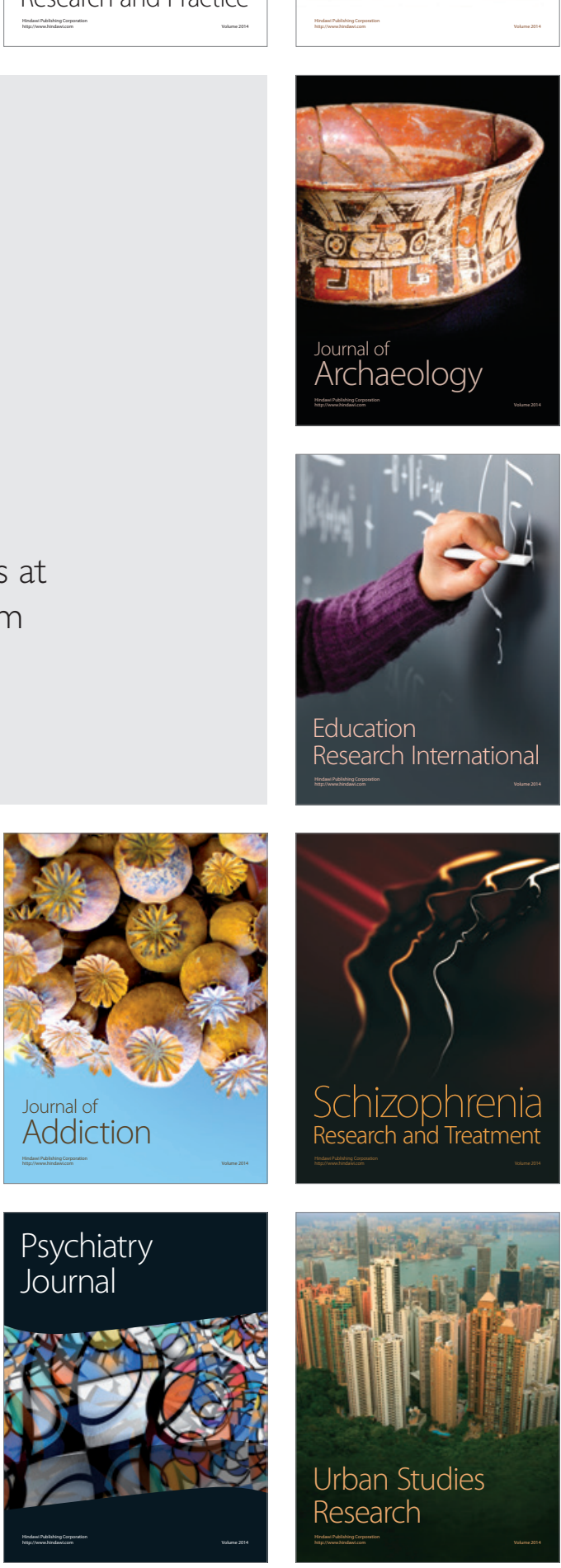